\title{
Intraneural perineurioma
}

INSERM

\section{Source}

INSERM. (1999). Orphanet: an online rare disease and orphan drug data base. Intraneural perineurioma. ORPHA:100003

Intraneural perineurioma is a rare tumor of cranial and spinal nerves arising from peripheral nerve sheet and composed exclusively or predominantly of cells showing perineurial differentiation. It presents as a localized, tubular or fusiform enlargement of a nerve or nerve segment, usually in the extremities or the trunk, associated with a motorpredominant mononeuropathy including slow, painless, gradual loss of motor function in the involved nerve trunk with muscle weakness and atrophy and, rarely, sensory dysfunction. Cranial nerve involvement is rare. 